\title{
THE ISSUE OF BALANCING INTERNAL COMBUSTION ENGINES WITH NON-CONVENTIONAL CRANK MECHANISM
}

It is possible to use not only classical crank mechanisms, but also non-conventional mechanisms in design of combustion engines. Balancing these mechanisms is a fundamental prerequisite of their proper function and long life. The concept of measuring system for balancing analysis is applied to a special type of piston machines with wobble mechanism. First part of the paper deals with description of FIK nonconventional mechanism (named after the inventors Fitz, Istenik, Kukuca), main parts and its functionality. Second part deals with measuring system, which is designed to measure dynamic parameters of non-conventional piston mechanism. The measuring system concept is applied to a special type of piston machines with wobble board. Analysis compares the three basic states, without balancing mass and with first and second type of balancing mass. Balancing system is determined from the calculation of the dynamical model. Design of balancing system and placement of sensor for acceleration measurement corresponds to the constructional possibilities of prototype model FIK.

Keywords: FIK mechanism, piston machine, balancing system.

\section{Introduction}

There are several types of mechanisms which are suitable for use in a Stirling heat engine. Main advantage of crank mechanism is relative design simplicity. Amount of experiences with mathematical modelling and dynamic calculations of crank mechanism allows its optimisation on the operating conditions [1 - 4]. The Stirling engines with non-conventional mechanisms have several advantages in practical applications, but the design of calculation model is often difficult [5 - 6].
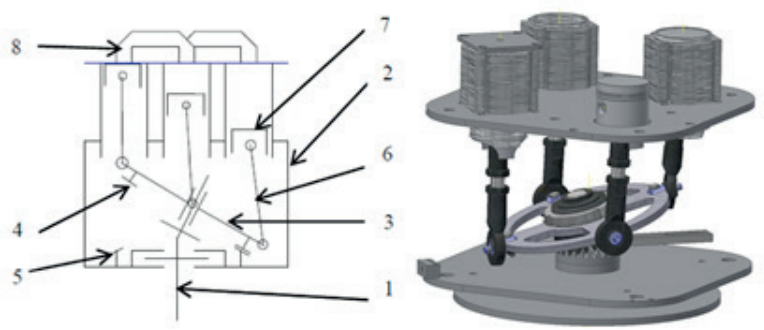

Fig. 1 Mechanism FIK: 1 - shaft, 2 - crankcase, 3 - swinging plate, 4 bevel wheel (part of swinging plate), 5 - bevel wheel (part of crankcase), 6 - ball joint segment, 7 - piston, 8 - head cylinder and regenerator pipe
FIK mechanism (Fig. 1) is a swinging system. Centre (centre of gravity) of the swinging plate makes circular motion during the rotation of the shaft. Bevel gear is used against parallel rotation of swinging plate with shaft. Reciprocating movement of the pistons is transformed to the rotational movement of shaft through ball joint segments [7]. This schematic and virtual representation was designed for application in type of a Stirling engine, specifically for alpha configuration [8].

\subsection{Basic dimensions for calculation of kinematic and dynamic parameters}

Basic dimensions of schematic model are the most important parameters for creating a kinematic model which is described by mathematical equations [9]. Figure 2 (left) shows some of basic dimensions and coordinate system. Main dimensions, their individual shortcuts and their values are:

- $\mathrm{Dv}=0.275 \mathrm{~m}$ - distance between opposite cylinders (distance of cylinder axis),

- $\mathrm{D}=0.075 \mathrm{~m}$ - bore,

- $\mathrm{Z}=0.069 \mathrm{~m}-$ stroke,

\footnotetext{
* ${ }^{1}$ Peter Baran, ${ }^{1}$ Pavol Kukuca, ${ }^{1}$ Dalibor Barta, ${ }^{1}$ Robert Labuda, ${ }^{2}$ Pawel Drozdiel, ${ }^{3}$ Saugirdas Pukalskas

${ }^{1}$ Department of Transport and Handling Machines, University of Zilina, Slovakia,

${ }^{2}$ Mechanical Engineering Faculty, Lublin University of Technology, Poland

${ }^{3}$ Department of Automobile Transport, Faculty of Transport Engineering, Vilnius Gediminas Technical University, Lithuania

E-mail: peter.baran@fstroj.uniza.sk
} 
- $\mathrm{R}=0.294 \mathrm{~m}$ - radius of base rolling cone,

- $\mathrm{Rko}=0.1346 \mathrm{~m}$ - distance between angle cranked axis of shaft and centre of lower ball joint centre,

- $\varphi=15^{\circ}$ - angle between main axis and axis of cranked part of the shaft.

Schematic view of engine (left part) and dynamic model with the specified points of the reduced mass (right part) are in Fig. 2 Masses of these specified points are:

- $\mathrm{mP}=0.6691 \mathrm{~kg}$ - reduced mass of the piston and connecting rods,

- $\mathrm{mAv}=0.572 \mathrm{~kg}$ - reduced mass of the connecting rods,

- msw. p a cs $=5.73 \mathrm{~kg}$ - reduced mass of the swinging plate and cranked part of the shaft.

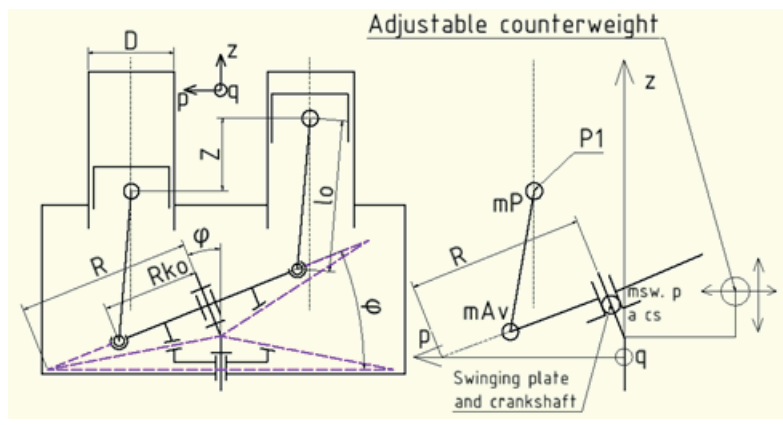

Fig. 2 Dynamic and modified schematic model

The formulas for computing trajectories of the point Av1 (first cylinder) in p-q-z directions in a polar coordinate system are:

$$
\begin{aligned}
p_{A v 1}= & R \cdot \cos \alpha_{t}-\left[\left(R-r_{A} \cdot \cos \left(\alpha_{t}-\beta_{A}\right)\right)\right. \\
& \cdot \cos \varphi \cdot \cos \alpha_{t}-\left(r_{A} \cdot \sin \left(\alpha_{t}-\beta_{A}\right) \cdot \sin \alpha_{t}\right], \\
q_{A v 1}= & R \cdot \sin \alpha_{t}-\left[\left(R-r_{A} \cdot \cos \left(\alpha_{t}-\beta_{A}\right)\right) \cdot\right. \\
& \cdot \cos \varphi \cdot \sin \alpha_{t}+\left(r_{A} \cdot \sin \left(\alpha_{t}-\beta_{A}\right) \cdot \sin \alpha_{t}\right]
\end{aligned}
$$$$
z_{A v 1}=\left[\left(R-r_{A} \cdot \cos \left(\alpha_{t}-\beta_{A}\right)\right) \cdot \sin \varphi\right]
$$

where: $\alpha_{\mathrm{t}}$ - rotation angle of shaft, $\mathrm{r}_{\mathrm{A}}$ - means Rko, $\beta_{\mathrm{A}}$ - fixed angular position of point Av1 to wobble plate.

Then formulas for calculating acceleration in p-q-z (general entry) are:

$a_{p A v 1}=\frac{d^{2}}{d t^{2}} p_{A v 1}, a_{q A v 1}=\frac{d^{2}}{d t^{2}} q_{A v 1}, a_{z A v 1}=\frac{d^{2}}{d t^{2}} z_{A v 1}$.

The resulting equation for calculating the stroke in point $\mathrm{P} 1$ is:

$$
\begin{aligned}
& z_{p}=\left(\left\{\left[R-r_{A} \cdot \cos \left(\alpha_{t}-\beta_{A}\right)\right] \cdot \sin \varphi\right\}\right)+ \\
& +l_{0} \cdot \cos \left\{\arcsin \left(\frac{\sqrt{\left(q_{A v 1}-q_{A 0}\right)^{2}+\left(p_{A v 1}-p_{P 0}\right)^{2}}}{l_{0}}\right)\right\},
\end{aligned}
$$

where: $1_{0}=0.193 \mathrm{~m}$ - length of ball joint segment (length of the connecting rod), $\mathrm{q}_{\mathrm{A} 0}, \mathrm{p}_{\mathrm{A} 0}$ - position in coordinates of the cylinder axis in the p-q plane.

Then formula for calculating of acceleration in $\mathrm{z}$ direction (general entry) is:

$a_{P}=\frac{d^{2}}{d t^{2}} z_{P}$

From the dynamic model were determined equations for the total inertial forces and its moments in p-q-z directions [10 - 11]. The courses of inertial forces and moments resulting from the final calculation of the dynamical model are shown in Fig. 3.

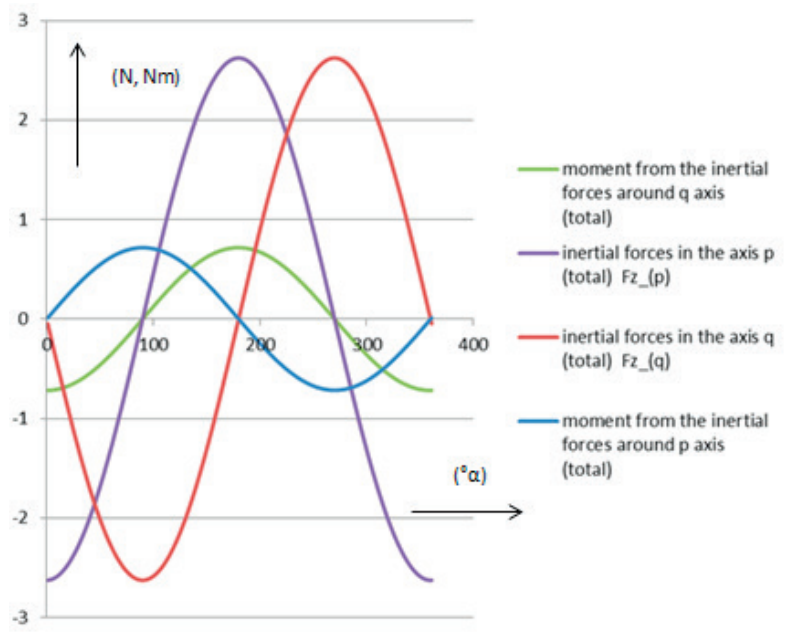

Fig. 3 Selected important resulting courses of inertial forces and moments (axes $p, q$ )

Following projections (Fig. 4) of the trajectory of the point Av1 in $\mathrm{p}-\mathrm{q}, \mathrm{p}-\mathrm{z}$ and $\mathrm{q}-\mathrm{z}$ planes were obtained from formulas (1), (2) and (3).

\section{Design of balancing mass}

Figure 5 shows a virtual model, real model and sensor placement (attaching of sensor in $\mathrm{p}$ axis).

Balancing system requires the following proposal of balancing mass:

- $\mathrm{r}_{\mathrm{v}}=0.15 \mathrm{~m}$ - the distance between the centre of gravity of balancing mass and shaft axis ( $\mathrm{z}$ - axis),

- $\mathrm{m}_{\mathrm{v}}=0.2 \mathrm{~kg}$ - the weight of balancing mass,

- $\mathrm{v}_{\mathrm{v}}=0.5 \mathrm{~m}$ - the distance between the centre of gravity of balancer mass and the plane p-q.

It is impossible to keep the distance $\mathrm{v}_{\mathrm{v}}=0.5 \mathrm{~m}$ for structural reasons (Fig. 5, virtual model, the distance between the upper and lower plates is $0.247 \mathrm{~m}$ ). Based on the above parameters the following alternative solutions were proposed. 

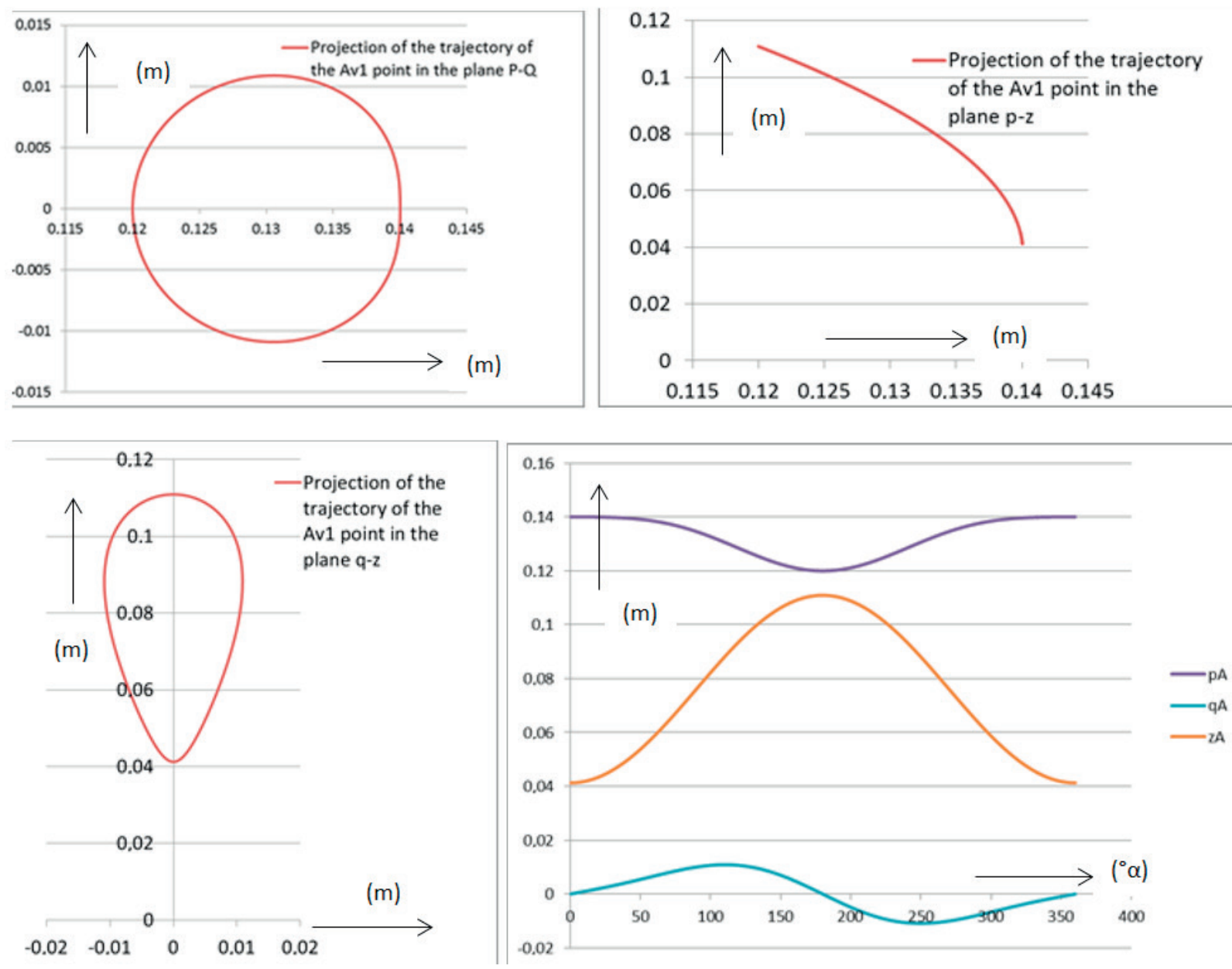

Fig. 4 Trajectories of Av1 point in p-q, p-z and q-z planes and the sequence of movements of the point Av1 according to the angle of rotation of the shaft
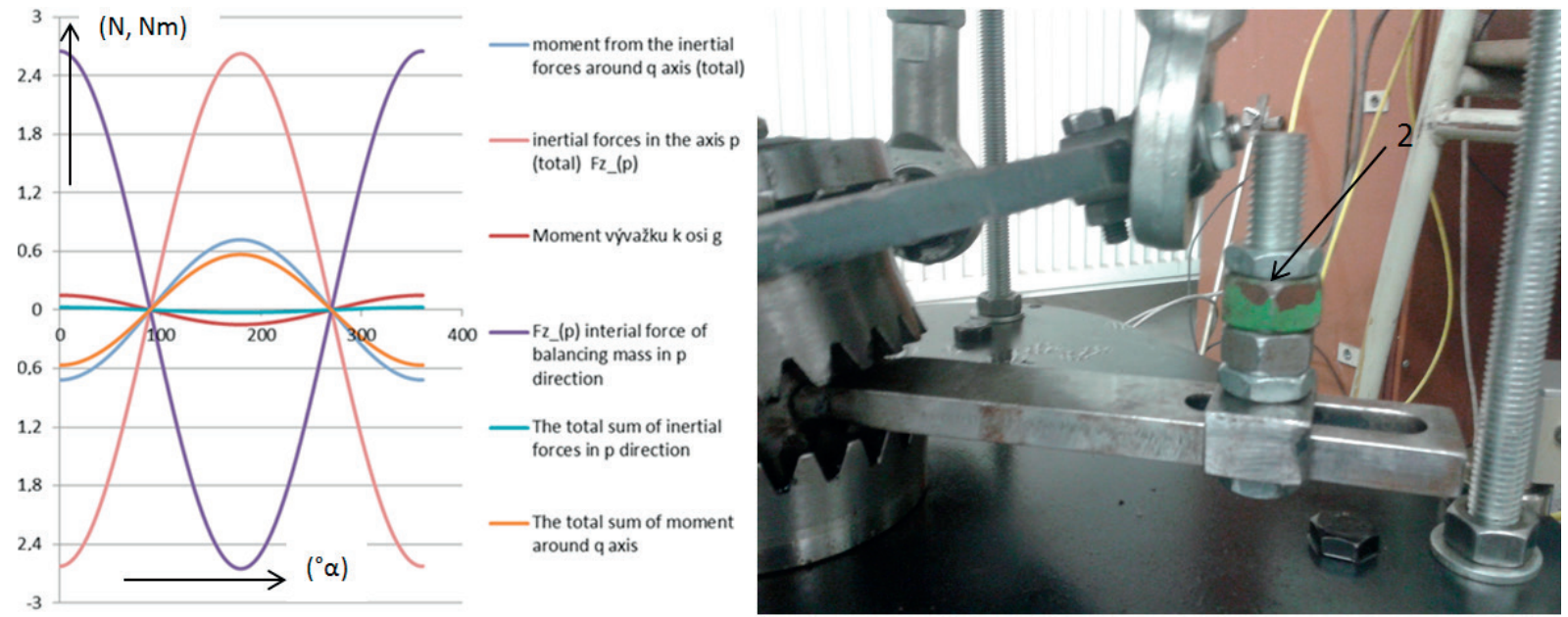

Fig. 5 Construction of a machine designed for the measurement of basic dynamic parameters and sensor placement (1-acceleration sensor $p$ direction) 


\section{First type of balancing mass}

This distance $\mathrm{v}_{\mathrm{v}}$ was modified to $0.07 \mathrm{~m}$ due to real possibilities of the machine structure and mounting of balancing mass. The balancing system is designed to eliminate the inertial forces in directions $\mathrm{p}$, and $\mathrm{q}$, but the total torque of the system is able to balance only partially. Inertial forces in the $\mathrm{z}$ direction and the total moment around $\mathrm{z}$ axis was ignored in the design of the balancing system (Fig. 6).
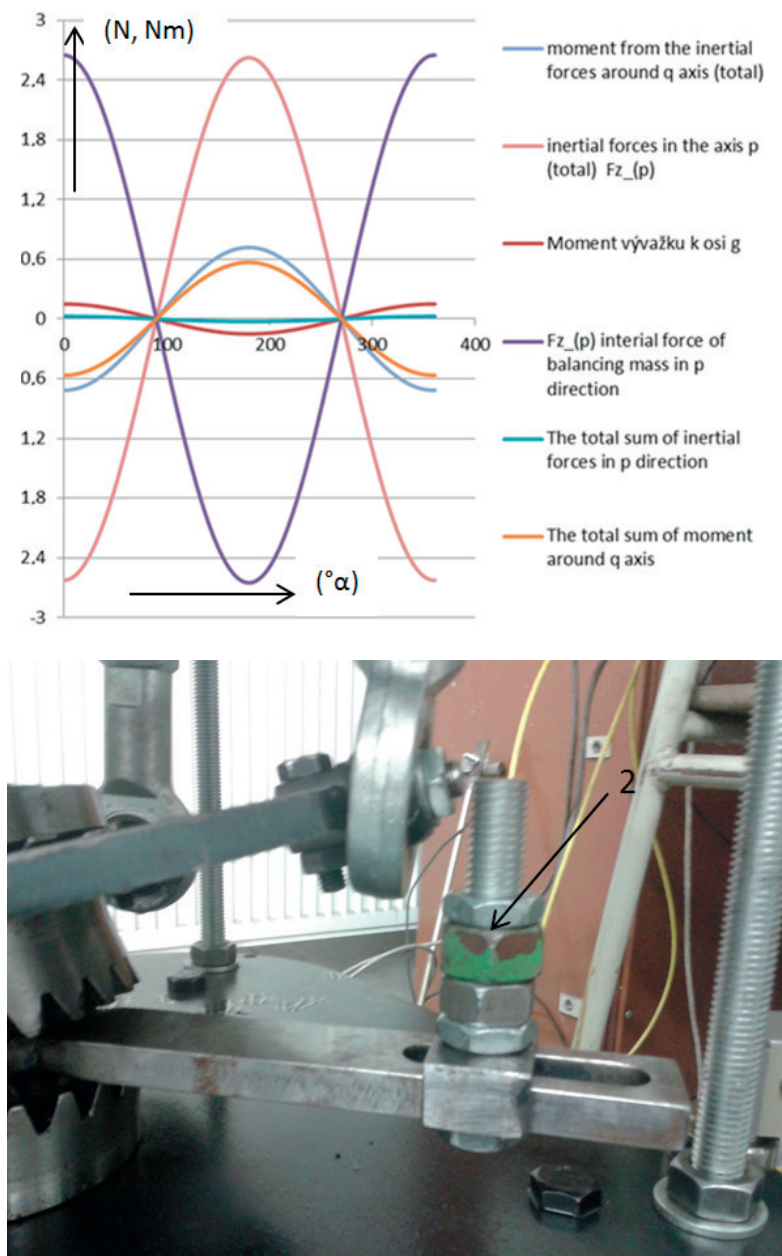

Fig. 6 Resulting courses with and without balancing mass (first type, left); Balancing system applied on real model (right), 2 - balancing mass

\section{Second type of balancing mass}

This balancing system was designed for better elimination of moments from inertial forces than the first type (this improvement was achieved by increasing the distance $\mathrm{v}_{\mathrm{v}}$ ), but it was impossible to keep the distance between the centre of gravity of the balancing mass and shaft axis (z-axis) as the first type, so the nearest possible distance $r_{v}$ was chosen (Fig. 7).
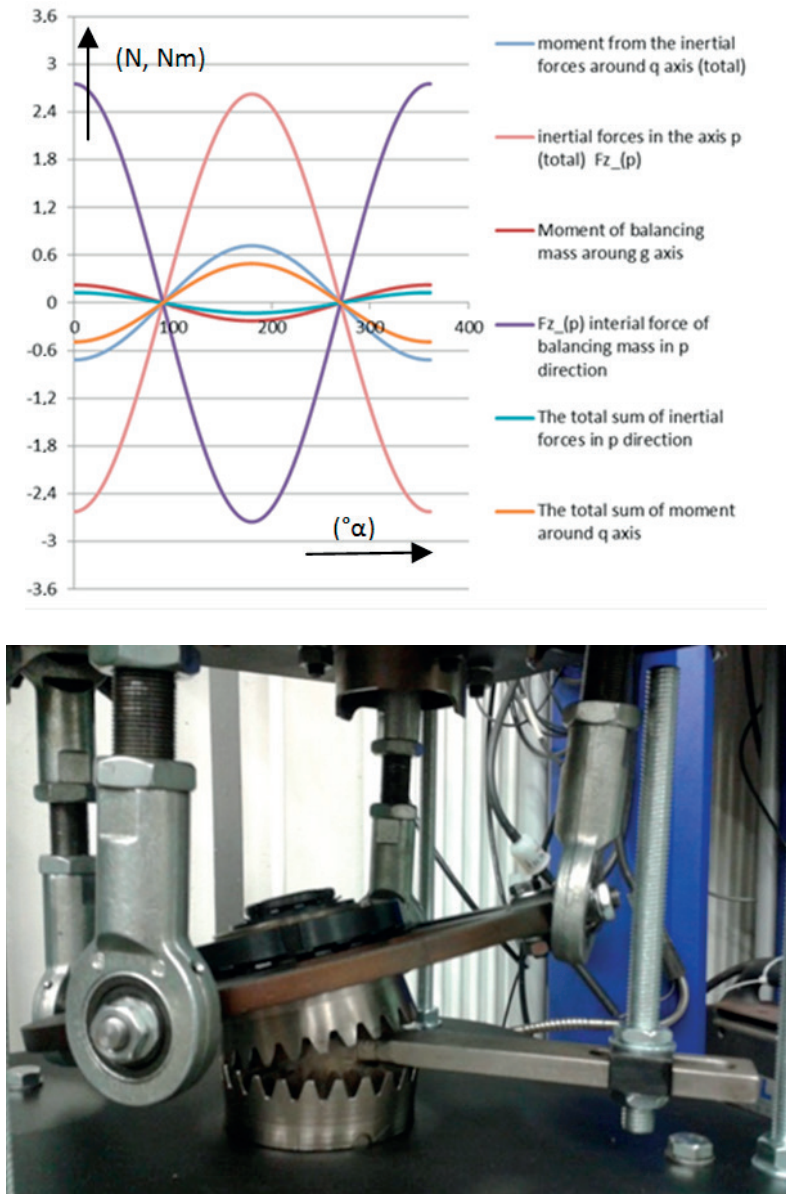

Fig. 7 Resulting courses with and without balancing mass (second type, left); Balancing system applied on real model (right)

The parameters for positioning and adjustment of the second type of balancing mass are:

- $\mathrm{r}_{\mathrm{v}}=0.155 \mathrm{~m}$ - the distance between the centre of gravity of the balancing mass and shaft axis (z-axis),

- $\mathrm{m}_{\mathrm{v}}=0.22 \mathrm{~kg}$ - weight of the balancing mass,

- $\mathrm{v}_{\mathrm{v}}=0.14 \mathrm{~m}$ - the distance between the centre of gravity of the balancing mass and the plane p-q.

\section{Measurement results}

Spectral analysis:

The measuring device VIBROTEST 60 (Fig. 8) was used for the measurement of spectral analysis. Basic settings of the device:

- spectral range $0-200 \mathrm{~Hz}$,

- averaging RMS, 


\section{COMMNICOIIONS}

- 1600 numbers of lines (device settings for integer values of frequencies by spectral range) [12 - 13].
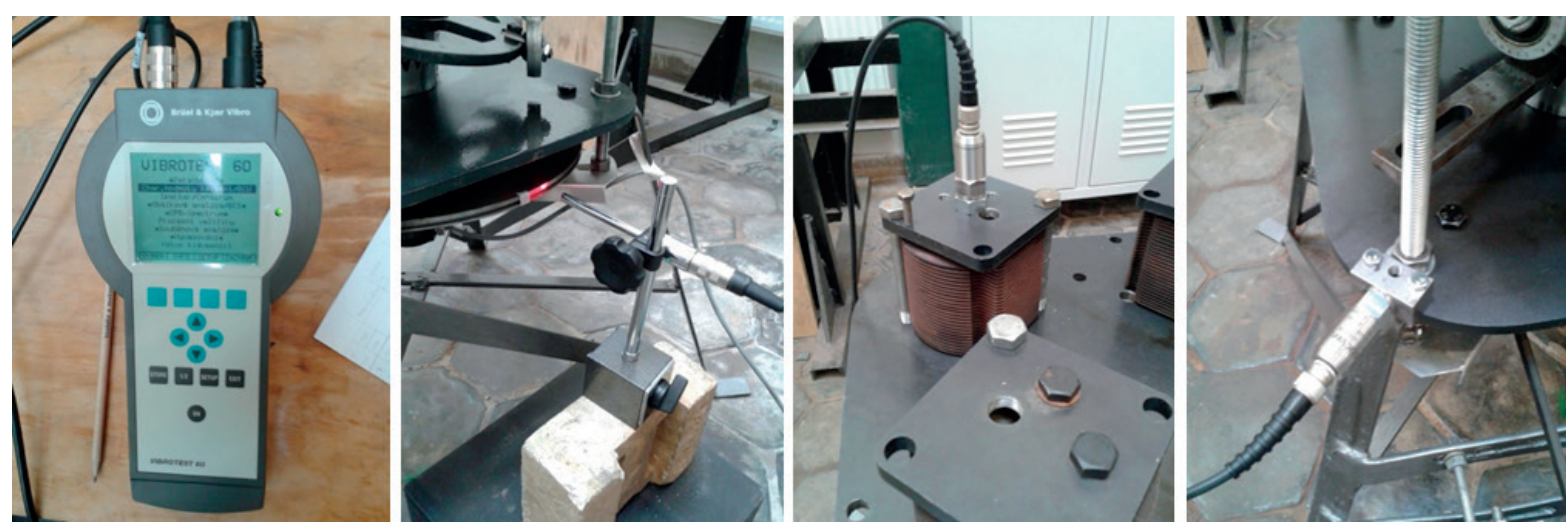

Fig. 8 Measurement device and positioning of RPM and acceleration sensors

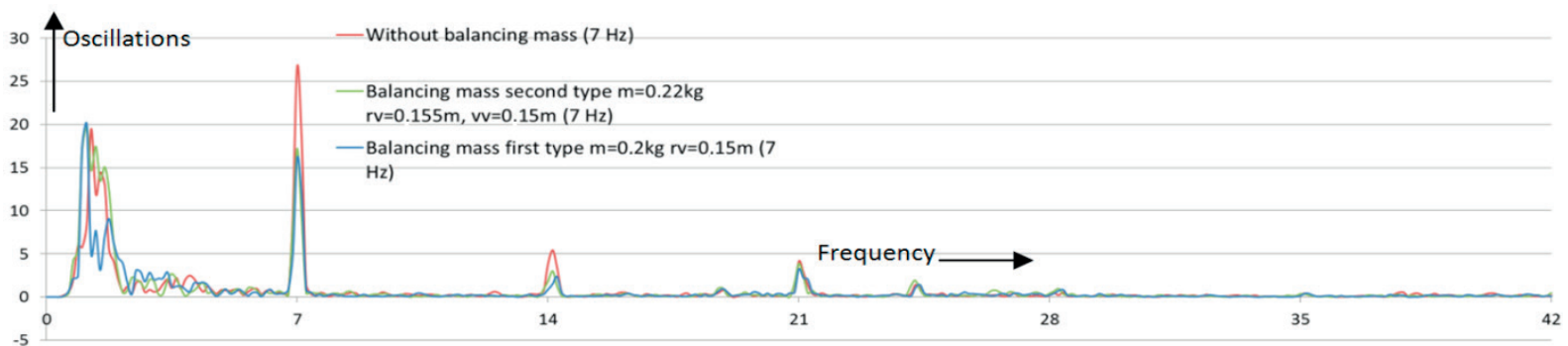

Fig. 9 Part of spectral analysis (420 RPM, 7Hz - excitation frequency, measurement of oscillations in $\mu \mathrm{m}$ ), $p$ direction

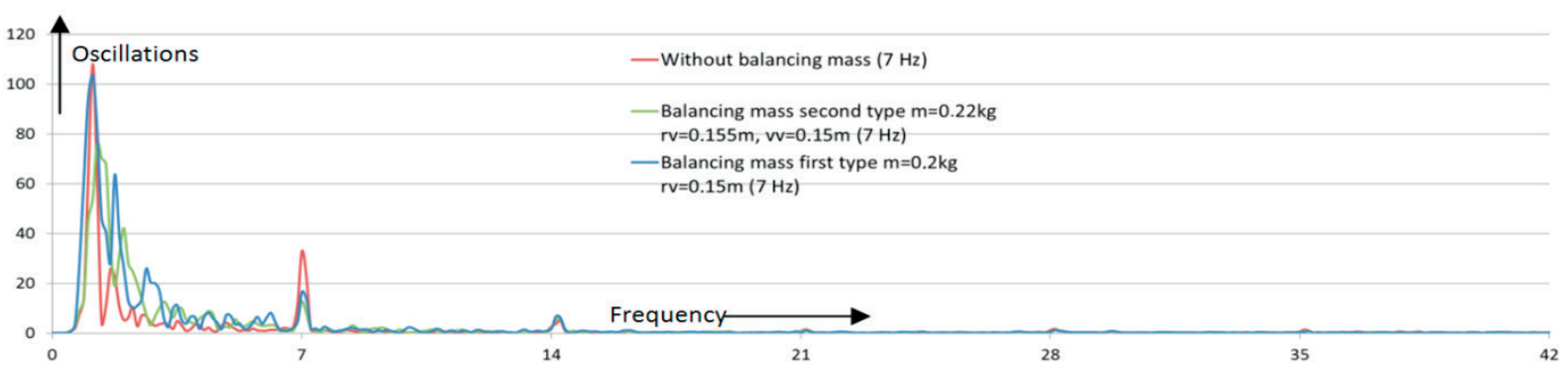

Fig. 10 Part of spectral analysis (420 RPM, $7 \mathrm{~Hz}$ - excitation frequency, measurement of oscillations in $\mu \mathrm{m}$ ), $z$ direction
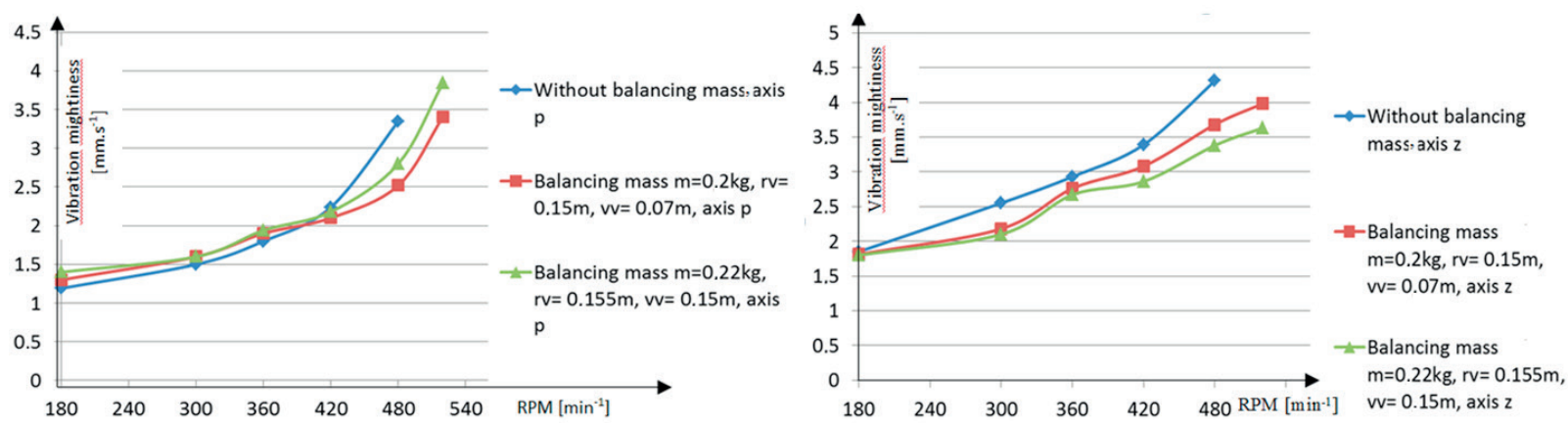

Fig. 11 Values of vibration mightiness, $p$ direction (left), $z$ direction (right) 
the first cylinder. The vibration mightiness is the most effective vibration velocity (in a given time interval) at selected locations [11]. Measurements of vibration mightiness were performed for purpose of comparing systems without and the system with balancing mass designed by the calculation [12]. The selected measurement time interval was 60 seconds (Fig 11).

\section{Conclusion}

It is clearly visible from the spectral analysis shown in Figs. 9 and 10 how big is the difference of oscillation courses for the measurement with and without balancing mass at the excitation frequency $7 \mathrm{~Hz}$. The course of the first type of balancing mass has worse elimination of the moment from inertial forces of piston group $\mathrm{P} 1$ in the $\mathrm{z}$ direction. It can be seen that balancing mass was able to eliminate the moments from inertial forces in the $\mathrm{z}$ direction at the excitation frequency of $7 \mathrm{~Hz}$ only partially. The courses of the second type of balancing mass in the $p$ direction has better elimination of inertia and oscillations in the $\mathrm{z}$ direction, but it was difficult to set the minimal position of the arm of balancing mass $\left(\mathrm{r}_{\mathrm{v}}\right)$. The measurements were performed also in other possible adjustments of the balancing system and it shows that with these two types of balancing masses was FIK machine able to achieve the highest RPM without endangering the stability of the model. There are visible significant differences in higher revolutions in the case of vibration mightiness measurement but interpretability of the results corresponds to the computational model as the results of spectral analysis show.

\section{Acknowledgement}

This article was supported by the project VEGA 1/0927/15 "Research of the use of alternative fuels and hybrid drives on traction vehicles with aim to reduce fuel consumption and air pollutants production" and project ITMS 26220220011 RAILBCOT - RAIL Vehicles Brake Components Test Stand based on the support of Research and Development Operational Program financed by European Fund of a Regional Development.

\section{References}

[1] BARAN, P., BREZANI, M., KUKUCA, P.: Measurement System and Diagnostic Applied to the Stirling Engine with Nonconventional Mechanism FIK, Zilina, 2015, ISBN 978-83-930944-7-9.

[2] HOLUBCIK, M., HUZVAR, J., JANDACKA, J.: Combined Production of Heat and Electricity with Use of Micro Cogeneration. IN-TECH 2011 - International Conference on Innovative Technologies, 2011, 200-202. ISBN 978-80-904502-6-4.

[3] DANEL, Q., PERILHON, C., PODEVIN, P., LACOUR, S., PUNOV, P., DESCOMBES, G.: Selection de fluide de travail d'un cycle de Rankine-Hirn en fonction du profil de temperature de la source chaude. Colloque Francophone en Energie, Environnement, Economie et Thermodynamique COFRET'14, Paris, France 2014, 557-565.

[4] MAKARAS, ROLANDAS, JONAS, KERŠYS, ARTÜRAS, PUKALSKAS, SAUGRIDAS: Dynamic model of a vehicle moving in the urban area, Transport. Vilnius Technika. ISSN 1648-4142. Vol. 26, no. 1 (2011), p. 35-42.

[5] STASTNIAK, P., HARUSINEC, J.: Computer Aided Simulation Analysis for Computation of Modal Analysis of the Freight Wagon. Communications - Scientific Letters of the University of Zilina, vol. 15, No. 4, 2013, 73-79. ISSN 1335-4205.

[6] LING, Q., HE, Y., HE, YUAN, et al.: Dynamic response of multibody structure subjected to blast loading. European journal of mechanics a-solids, vol. 64, Published JUL-AUG 2017.

[7] BARTA, D., SANIGA, J., MRUZEK, M., KENDRA, M.: Design of Selected Parts of Non-Conventional Stirling Engine with FIK Mechanism. The Online J. of Science and Technology, vol. 3, No. 2, 2013, 129-139. ISSN 2146-7390.

[8] ISTENIK, R.: Distribution and Non-Conventional Mechanisms of Combustion Engines. Zilina, 2008, 162-169.

[9] WANG, H., YU, W., CHEN, G.: An approach of topology optimization of multi-ridig-body mechanism. Computed aided design, vol. 84, Published: MAR 2017

[10] ISTENIK, R., BARTA, D., MUCHA, W.: Influence of the Wheels on the Automobile Dynamics. Communications - Scientific Letters of the University of Zilina, vol. 6, No. 1, 2004, 26-28. ISSN 1335-4205.

[11] DIZO, J., BLATNICKY, M., SKOCILASOVA, B.: Computational Modelling of the Rail Vehicle Multibody System Including Flexible Bodies. Communications - Scientific Letters of the University of Zilina, vol. 17, No. 3, 2015, 31-36. ISSN 1335-4205.

[12] KREIDL, M., SMID, R.: Technical Diagnostic, Prague, 2006, 408. ISBN 80-7300-158-6.

[13] JEDLINSKI, L., CABAN, J., KRZYWONOS, L., WIERZBICKI, S., BRUMERCIK, F.: Application of Vibration Signal in the Diagnosis of IC Engine Valve Clearance. J. of Vibroengineering, vol. 17, No. 1, 2015, 175-187. 